\title{
Dietary fibre intake and risk of cardiovascular disease: systematic review and meta-analysis
}

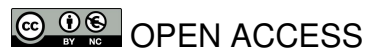

\begin{abstract}
Diane E Threapleton doctoral student ${ }^{1}$, Darren C Greenwood senior lecturer in biostatistics ${ }^{2}$, Charlotte E L Evans lecturer in nutritional epidemiology ${ }^{1}$, Christine L Cleghorn research fellow ${ }^{1}$, Camilla Nykjaer research assistant ${ }^{1}$, Charlotte Woodhead research assistant ${ }^{1}$, Janet E Cade professor of nutritional epidemiology group ${ }^{1}$, Christopher $\mathrm{P}$ Gale associate professor of cardiovascular health sciences ${ }^{2}$, Victoria J Burley senior lecturer in nutritional epidemiology ${ }^{1}$
\end{abstract}

${ }^{1}$ Nutritional Epidemiology Group, School of Food Science and Nutrition, University of Leeds, Leeds LS2 9JT, UK ; ${ }^{2}$ Centre for Epidemiology and Biostatistics, University of Leeds, UK

\begin{abstract}
Objective To investigate dietary fibre intake and any potential dose-response association with coronary heart disease and cardiovascular disease.
\end{abstract}

Design Systematic review of available literature and dose-response meta-analysis of cohort studies using random effects models.

Data sources The Cochrane Library, Medline, Medline in-process, Embase, CAB Abstracts, ISI Web of Science, BIOSIS, and hand searching.

Eligibility criteria for studies Prospective studies reporting associations between fibre intake and coronary heart disease or cardiovascular disease, with a minimum follow-up of three years and published in English between 1 January 1990 and 6 August 2013.

Results 22 cohort study publications met inclusion criteria and reported total dietary fibre intake, fibre subtypes, or fibre from food sources and primary events of cardiovascular disease or coronary heart disease.

Total dietary fibre intake was inversely associated with risk of cardiovascular disease (risk ratio 0.91 per $7 \mathrm{~g} /$ day $(95 \%$ confidence intervals 0.88 to 0.94$)$ ) and coronary heart disease ( 0.91 ( 0.87 to 0.94$)$ ). There was evidence of some heterogeneity between pooled studies for cardiovascular disease $\left(I^{2}=45 \%(0 \%\right.$ to $\left.74 \%)\right)$ and coronary heart disease $\left(I^{2}=33 \%(0 \%\right.$ to $\left.66 \%)\right)$. Insoluble fibre and fibre from cereal and vegetable sources were inversely associated with risk of coronary heart disease and cardiovascular disease. Fruit fibre intake was inversely associated with risk of cardiovascular disease.

Conclusions Greater dietary fibre intake is associated with a lower risk of both cardiovascular disease and coronary heart disease. Findings are aligned with general recommendations to increase fibre intake. The differing strengths of association by fibre type or source highlight the need for a better understanding of the mode of action of fibre components.

\section{Introduction}

In recent years, a decline in the incidence of cardiovascular disease (CVD) and coronary heart disease (CHD) has been seen both among some European countries and also in the United States. ${ }^{1-3}$ Although rates of CVD have long since peaked for many developed countries and mortality from the disease is declining, ${ }^{4}$ it still accounts for almost half (48\%) of all deaths in Europe and a third (32.8\%) of all deaths in the US. ${ }^{2} 3$

In the 1970s, the protective link was proposed between dietary fibre (in the form of whole grain foods) and ischaemic heart disease. ${ }^{5}$ Many observational and experimental studies have since examined the relation between dietary fibre or fibre rich foods and total cardiovascular risk or cardiovascular risk factors-such as hypertension, central obesity, insulin sensitivity, and elevated plasma cholesterol. ${ }^{67}$

The protective effect of dietary fibre on risk of CVD and CHD is biologically plausible, and there are many potential mechanisms through which fibre may act on individual risk factors. Soluble, viscous fibre types can affect absorption from the small intestine because of the formation of gels that attenuate postprandial blood glucose and lipid rises. ${ }^{89}$ The formation of gels also slows gastric emptying, maintaining levels of satiety and contributing towards less weight gain. ${ }^{89}$ Soluble fibre and resistant starch molecules are additionally fermented by bacteria in the large intestine, producing short chain fatty acids, which help reduce circulating cholesterol levels. ${ }^{10}$ 
In addition to fibre, many other potentially beneficial compounds within high fibre foods could have protective effects. For example, compounds in grains such as antioxidants, hormonally active lignans, phytosterols, amylase inhibitors, and saponins have all been shown to influence risk factors for CHD, and the combination of compounds within grains could be responsible for their protective effect. ${ }^{11}$

The aim of this work was to review literature published since 1990 , in generally healthy populations, concerning dietary fibre intake and cardiovascular risk, and to update reports published in the United Kingdom by the Committee on Medical Aspects of Food Policy, in the early 1990s. ${ }^{12} 13$

\section{Methods}

\section{Search strategy}

We conducted literature searches for articles published from 1 January 1990 to 6 August 2013. Initial literature searching was part of a larger systematic review concerning studies reporting associations between any form of carbohydrate intake and cardiometabolic health outcomes (between 1 January 1990 to 17 November 2009). Searches were conducted by an information specialist in addition to other members of the research team (VJB, DET, CLC). We used six electronic databases: the Cochrane Library, Medline, Medline in-process, Embase, CAB Abstracts, ISI Web of Science, and BIOSIS. This search was extended from 2009 using Medline, Medline in-process, and Embase, which were the main sources of included articles in the initial search. This update searching was carried out only for articles reporting dietary fibre and CVD or CHD. We used the same key search terms including, among others, "dietary fibre," "cellulose," "lignin," various other subfractions and subtypes of fibre, "cardiovascular diseases," "coronary diseases," and "myocardial ischaemia" (web fig 1). Hand searching of selected journals and cross checking of bibliographies from other published review articles was also done to supplement the electronic searches. Standard guidelines for conducting and reporting meta-analyses of observational studies were followed. ${ }^{14}$

\section{Study selection}

After removal of duplicate references, initial screening of article titles and abstracts was undertaken by members of the review team (DET, CLC, CELE, VJB). This process removed those articles that were clearly not relevant-such as editorials, single case study reports, and therapeutic approach articles. Reviewers used prespecified guidelines to ensure a consistent approach. Potentially relevant articles were obtained in full text and read independently by two review team members (DET, CLC, CELE, $\mathrm{CN}, \mathrm{VJB}$ ) using a structured flow chart and detailed guidelines to determine eligibility for inclusion. Any disagreements were settled by a third reviewer. We obtained copies of all articles identified as being of potential importance, including contacting authors as necessary.

Articles eligible for inclusion were reported in English language since 1990 and were original research from prospective observational studies, with at least three years' follow-up. Studies had to report incident or fatal events of primary CHD or CVD in relation to dietary fibre intake.

Because primary prevention of CVD was the main focus for this work (rather than secondary prevention), we excluded studies if participants had been specifically recruited because of ill health or history of disease and if the study did not recruit from a generally healthy population.
Multiple reports from the same cohort study were reviewed, and papers with the longest follow-up for identical outcomes were included. If insufficient data were presented at the longer follow-up for inclusion in meta-analysis, we used the shorter follow-up data.

Methodological quality of studies was evaluated using the Newcastle-Ottawa Scale for assessing cohort studies used in meta-analyses. ${ }^{15}$ Studies were not excluded based on these scores, but aspects of study quality-such as follow-up duration, case ascertainment, and adjustment for various important confounders-were investigated through meta-regression.

\section{Data extraction}

Data from articles were extracted directly into a Microsoft Access database, which included predefined fields set up to capture aspects of study design and quality as well as all results (relative risks and confidence intervals). We also extracted details on exposure type and quantity, case numbers, the definition of outcome, and adjustments used within analyses. This method of data extraction was based on the approach used for the World Cancer Research Fund second expert report. ${ }^{16}$ Multiple risk estimates were extracted from most publications, because risk of CHD or CVD was provided for a range of fibre subtypes and sources as well as for total dietary fibre. Risk ratios plus $95 \%$ confidence intervals for continuous (linear) exposures were extracted preferentially or, where these data were not available, risk estimates across increasing fibre intake categories were extracted.

\section{Statistical methods}

Included studies use a range of different definitions for their exposure categories. We therefore derived an estimated dose-response trend for each study, using the method recommended by Greenland and Longnecker. ${ }^{17}$ These dose-response trends were then combined using random effects meta-analysis. This method generates study specific slopes (with 95\% confidence intervals), based on the results presented for each category of fibre intake. To derive a linear dose-response curve for each study, the distribution of cases and person years, or cases and non-cases, with risk ratios and estimates of uncertainty (for example, confidence intervals) for at least three categories of quantified fibre intake needed to be presented in the reviewed publication. If the total number of cases or person years was presented, but not the distribution, we estimated the distribution on the basis of definitions of the quantiles. The median or mean level of fibre intake was then assigned to the corresponding risk ratio for each study. When medians and means were not presented, we used the category midpoint. Where the highest or lower category was unbounded, we assumed the width of the category to be the same as the next adjacent category, so that we could assign a midpoint. If studies already reported a linear dose-response trend, with confidence intervals or standard error, this was used directly.

If results were only presented separately for men and women, we derived separate dose-response curves. These curves were then combined into a single estimate for the study using a fixed effects meta-analysis, before combining with the other studies using a random effects meta-analysis. This method maintained the correct degrees of freedom for tests of heterogeneity.

Heterogeneity between studies was tested using Cochran's Q statistic, alongside the proportion of total variation in study estimates that is due to heterogeneity $\left(\mathrm{I}^{2}\right) .{ }^{18}$ Pooled estimates are only presented if $\mathrm{I}^{2}$ did not exceed our prespecified cut point of $75 \%$ and if studies had included appropriate adjustments. For 
comparability, fibre increments presented in the dose-response figures were chosen to be approximately one standard deviation of the mean, based on European population intakes, from multiple sources. ${ }^{19-22}$ Increments are equivalent to Association of Official Analytical Chemist (AOAC) fibre values, because most contributing studies assessed fibre in this way. ${ }^{23}$

We explored other methodological features through predefined meta-regression. These included fibre intake assessment method (AOAC or non-AOAC); inclusion of non-fatal events; follow-up duration ( $<10$ years or $\geq 10$ years); geographical location (Americas, Europe, or other); and whether the results were adjusted for age, alcohol, anthropometry, energy intake, physical activity, or sex. All analyses were performed in Stata 12.1. ${ }^{24}$

The potential for small study effects such as publication bias was explored using funnel plots with Egger's test of asymmetry ${ }^{25}$ where there were sufficient studies to allow the test.

We plotted non-linear dose-response curves using restricted cubic splines for each study, with knots fixed at percentiles $10 \%, 50 \%$, and $90 \%$ through the distribution, and the median intake as the reference. ${ }^{26}{ }^{27}$ These curves were combined using multivariate meta-analysis ${ }^{28}$ and the summary curve was plotted, with $95 \%$ confidence limits, using the median over all studies as the reference. Studies with three or fewer categories could not be included in this analysis.

\section{Results}

\section{Literature search}

We identified 26 publications in total: 14 from the main search plus 12 from the update (web fig 2). Of these papers, four reported only baseline fibre intakes in those subsequently classified as cases or non-cases and will not be discussed here further, because results were either unadjusted or minimally adjusted. ${ }^{29-32}$

In total, we identified 19 publications from 17 cohort studies that provided risk estimates for total dietary fibre intake and incident or fatal events of CVD or CHD. $.^{21} 2233-49$ Three additional publications were identified that reported risk of CVD or CHD in relation to only cereal fibre intake. ${ }^{50-52}$ Results from the Scottish Heart Health Study could not be pooled because only data for fibre density (g/4.18 MJ) were reported and it was not possible to quantify intakes in each consumption category. ${ }^{46}$

\section{Included study characteristics}

The cohorts were largely from the US ${ }^{35} 41-44495152$ or Europe $^{2122} 3334373845-48$ in addition to two Japanese ${ }^{39} 40$ and one Australian study ${ }^{36}{ }^{50}$ (table $\downarrow$ ). Dietary intakes tended to be assessed with food frequency questionnaires, with the exceptions of the National Health and Nutrition Examination Survey I study, Zutphen Elderly study, and Malmo Diet and Cancer Cohort, in which recalls or diet histories were taken. ${ }^{21} 3547$ The Norfolk branch of the European Prospective Investigation into Cancer and Nutrition (EPIC) presented results for diet assessed both with food frequency questionnaires and seven day food diaries. ${ }^{48}$

Estimates of fibre intake were generated using values derived with the AOAC method in most studies, ${ }^{2134-44} 47$ 49-52 with one Finnish study and four UK studies classifying fibre as non-starch polysaccharide only. ${ }^{22} 33344648$ One study included risk estimates with total fibre assessed both as non-starch polysaccharide and using the AOAC method, and risk estimates for food sources of fibre assessed only as non-starch polysaccharide. ${ }^{45}$
The quality of studies included in meta-analyses was assessed by applying the Newcastle-Ottawa scale for cohort studies. ${ }^{15}$ Web figure 3 lists details of how the criteria were applied to cohort studies reporting dietary fibre intake and CVD. Web table 1 presents the scores assigned to each included study. Lower scoring studies had not assessed diet using structured interviews, had not recruited a representative sample of the community, and either did not report losses to follow-up or had not reported whether participants with prevalent disease were excluded from analyses. All studies had adjusted for appropriate potential confounders, had drawn non-cases from the same population as cases, had adequate follow-up time between dietary assessment and outcomes, and also reported that outcomes were obtained from medical records or through record linkage.

\section{Total fibre intake and risk of CHD}

Twelve of 15 publications reporting coronary event risk and total fibre intake were included in the dose-response meta-analysis. ${ }^{21} 223538-4244454749$ Results for incident events from the Norfolk arm of the EPIC study ${ }^{48}$ were not included, because fatal cases were additionally included in another publication that reported on all EPIC centres. ${ }^{38}$ As discussed above, results from the Scottish Heart Health Study could not be pooled. ${ }^{46}$ Results from the Oxford Vegetarian Study ${ }^{34}$ were also not included in the meta-analysis because participants from this cohort had been invited to participate in the Oxford branch of the EPIC study, ${ }^{53}$ which formed part of another included cohort. ${ }^{37}$ The pooled estimate for the risk ratio per $7 \mathrm{~g} /$ day increase in fibre was 0.91 (95\% confidence interval 0.87 to 0.94 ) with evidence of moderate heterogeneity between studies $\left(\mathrm{I}^{2}=33 \%\right.$, $0 \%$ to $66 \%$; fig $1 \Downarrow)$. The dose-response curve showed that lower CHD risk was associated with greater intakes of total fibre but confidence intervals around the estimate widened towards the upper intake levels, where data were sparse. Therefore, interpretation of risk at these higher intakes should be undertaken cautiously (fig $2 \Downarrow$ ).

\section{Total fibre intake and risk of CVD}

Ten publications reported CVD risk (fatal or incident stroke plus CHD) and total dietary fibre intake, all of which were included in the dose-response meta-analysis. ${ }^{33}$ 35-37 39-41 434547 Each study used different criteria to classify CVD cases. Five studies included any circulatory condition (equivalent to ICD-10 (international classification of diseases, 10th revision) I00-I99) 3336373940 and five studies seemed to use narrower definitions. ${ }^{36} 4143457$ The pooled risk ratio per $7 \mathrm{~g} /$ day increase in fibre was 0.91 (95\% confidence interval 0.88 to 0.94$)$, with some evidence of heterogeneity between studies $\left(\mathrm{I}^{2}=45 \%, 0 \%\right.$ to $74 \%$; fig $3 \Downarrow$ ). The dose-response curve for total fibre intake and CVD (fig $4 \Downarrow$ ) seemed to show that event risk fell steadily with increasing total fibre intake.

For easy comparison between risk estimates for the different fibre exposures, figure $5 \Downarrow$ displays the combined risk estimates for both CHD and CVD with greater intake of total fibre, insoluble, soluble, and sources of fibre (cereal, fruit, or vegetable). The dose-response increments differ with each exposure to reflect the mean standard deviation among the populations. Web figures 4-8 include full forest plots and restricted cubic spline figures for each meta-analysis, other than total fibre (figs 1-4). 


\section{Insoluble fibre intake and risk of CHD or CVD}

Of six publications reporting CHD risk and insoluble fibre intake, five were included in the meta-analysis. ${ }^{22} 39414445$ Results from the Japan Public Health Centre-based Cohort could not be included in the meta-analysis because the study reported risk in different intake categories but did not provide values for insoluble fibre in the groups. ${ }^{40}$ The pooled estimate for the risk ratio per $7 \mathrm{~g} /$ day increase in insoluble type fibre was $0.82(95 \%$ confidence interval 0.68 to 0.99$)$ with evidence of reasonably high heterogeneity $\left(\mathrm{I}^{2}=72 \%, 32 \%\right.$ to $89 \%$; fig 5 and web fig 4A).

Three studies reported CVD risk and insoluble fibre intake and all were included in the meta analysis (fig 5 and web fig 4C). ${ }^{39}{ }^{41} 45$ For each $7 \mathrm{~g} /$ day increase in insoluble fibre intake, the combined risk ratio for CVD was the same as with CHD $(0.82,95 \%$ confidence interval 0.70 to 0.96$)$. There was some evidence of heterogeneity between the studies $\left(\mathrm{I}^{2}=46 \%, 0 \%\right.$ to $84 \%)$.

From the restricted cubic splines (web figs 4B and 4D), CHD and CVD risk can be seen to gradually lessen with ever higher intakes of insoluble fibre. Interpretation of risk from these figures, especially at higher intake levels, should be cautiously undertaken because data across the intake range were sparse and were available only in five or three studies, respectively.

\section{Soluble fibre intake and risk of CHD or CVD}

Of seven cohorts reporting CHD risk and intake of water soluble fibre, six were included in the meta-analysis. ${ }^{22} 3539414445$ Again, results from the Japan Public Health Centre-based Cohort were not included because no estimate of soluble fibre intake was presented. ${ }^{40}$ The pooled estimate for the risk ratio per $4 \mathrm{~g} / \mathrm{day}$ increase in soluble type fibre was 0.89 (95\% confidence interval 0.78 to 1.02$)$, with evidence of moderate heterogeneity $\left(\mathrm{I}^{2}=47 \%\right.$, $0 \%$ to $79 \%$; fig 5 and web fig $5 \mathrm{~A}$ ). The cubic spline graph (web fig 5B) shows a non-significant reduction in CHD risk with increasing soluble fibre intake; confidence intervals around the estimate remained wide across intake levels because data were thinly spread.

All four studies that reported CVD risk in relation to intake of soluble fibre could be included in the meta-analysis. ${ }^{35} 394145$ The combined estimate for the risk ratio from these studies was 0.88 (95\% confidence interval 0.75 to 1.03 ), with evidence of moderate heterogeneity $\left(\mathrm{I}^{2}=58 \%, 0 \%\right.$ to $86 \%$; fig 5 , web figs $5 \mathrm{C}$ and 5D).

\section{Cereal fibre intake and risk of CHD or CVD}

CHD risk in relation to cereal fibre intake was reported in 12 publications, of which nine were included in the meta-analysis. ${ }^{21} 2238394142444552$ Results from the EPIC Norfolk study ${ }^{48}$ were not included because this cohort had been included in the pooled EPIC estimate..$^{38}$ Two results from the Nurses' Health Study were identified; the results from Bernstein and colleagues $^{52}$ were included over those from Wolk and colleagues ${ }^{49}$ because of longer follow-up. Bernstein and colleagues reported several hazard ratios calculated by using several methods, and the result derived from the cumulative average intake was used because it was most consistent with the other studies. Results from the Australian Blue Mountain Eye Study were not included because data presented were insufficient to derive a dose-response trend. ${ }^{50}$ The pooled estimate for the risk ratio per $7 \mathrm{~g}$ /day increase in fibre from cereal sources was 0.84 (95\% confidence interval 0.76 to 0.94$)$ with evidence of heterogeneity between studies $\left(\mathrm{I}^{2}=65 \%, 29 \%\right.$ to $83 \%$; fig 5 and web fig $6 \mathrm{~A}$ ). The dose-response curve (web fig 6B) showed that lower CHD risk continued to be associated with higher intakes of fibre from cereals, although data were concentrated around lower intake levels and thus less weight should be placed on risk estimates at higher intakes.

Data from five of six studies reporting cereal fibre intake and CVD risk could be incorporated into the pooled estimate. $^{36} 37414551$ The risk ratio per $7 \mathrm{~g} /$ day greater intake of cereal fibre was 0.92 (95\% confidence interval 0.84 to 1.00), with evidence of relatively low heterogeneity $\left(\mathrm{I}^{2}=15 \%, 0 \%\right.$ to $82 \%$; fig 5, web figs $6 \mathrm{C}$ and $6 \mathrm{D}$ ).

\section{Fruit fibre intake and risk of CHD or CVD}

Nine of 10 publications that reported fibre intake from fruit and CHD risk were included in the meta-analysis. ${ }^{21} 2238394142444549$ The results reported in the EPIC Norfolk paper were again not included. ${ }^{48}$ The pooled estimate for the risk ratio per $4 \mathrm{~g} /$ day increase in fibre from fruit was 0.92 (95\% confidence interval 0.83 to 1.01 ), with evidence of substantial heterogeneity between studies ( $\mathrm{I}^{2}=62 \%, 22 \%$ to $82 \%$; fig 5 and web fig $\left.7 \mathrm{~A}\right)$.

Data from four studies were included in the meta-analysis for fruit fibre intake and CVD risk. ${ }^{36} 374145$ One additional study could not be included in the meta-analysis because only a comparison of highest and lowest categories of fruit fibre intake was presented. ${ }^{43}$ For each $4 \mathrm{~g} /$ day greater intake of fruit fibre, the risk ratio was 0.96 ( $95 \%$ confidence interval 0.93 to 1.00 ), with no evidence of excess heterogeneity between the studies $\left(\mathrm{I}^{2}=0 \%, 0 \%\right.$ to $84 \%$; fig 5 and web fig $7 \mathrm{C}$ ).

The dose-response curve indicates that lower risk of CHD or CVD is associated with higher fruit fibre intakes of up to around 5-8 g/day, which is equivalent to about two to four servings of fruit. ${ }^{9}$ There was some evidence of possible threshold effects where the lines for the dose-response figures flattened over higher intakes (web figs 7B and 7D). But again, data were sparse at the upper intake levels and should be interpreted cautiously.

\section{Vegetable fibre intake and risk of CHD or CVD}

Nine of 10 publications that reported vegetable fibre intake and CHD risk were included in the meta-analysis. ${ }^{21} 2238394142444549$ Again, the results from EPIC Norfolk were not included here. ${ }^{48}$ Most studies did not report whether potatoes were included within the classification of vegetables, with the exception of four publications which did not include potatoes. ${ }^{21} 384145$ The pooled estimate for the risk ratio per $4 \mathrm{~g} /$ day increase in fibre from vegetable sources was 0.94 (95\% confidence interval 0.89 to 1.00$)$, with no evidence of excess heterogeneity between studies $\left(\mathrm{I}^{2}=0 \%, 0 \%\right.$ to $29 \%$; fig 5 and web fig $\left.8 \mathrm{~A}\right)$.

Data from four studies were included in the meta-analysis for vegetable fibre intake and CVD risk. ${ }^{36} 374145$ Again, one additional study could not be included in the meta-analysis because only a comparison of highest and lowest categories of vegetable fibre intake was presented. ${ }^{43}$ For each 4 g/day greater intake of vegetable fibre, the risk ratio was 0.92 (95\% confidence interval 0.87 to 0.96 ), with no evidence of excess heterogeneity between the studies ( $\mathrm{I}^{2}=0 \%, 0 \%$ to $58 \%$; fig 5 and web fig $8 \mathrm{C}$ ).

Similar to the dose-response curves for fruit fibre, lower risk of CHD and CVD was each associated with greater intakes of vegetable fibre, up to intakes about $6 \mathrm{~g} /$ day for CHD or $10 \mathrm{~g} /$ day for CVD. These values would be roughly equivalent to the fibre in four to six portions of vegetables, ${ }^{9}$ but again, data became sparse at higher intakes and confidence intervals widened (web figs $8 \mathrm{~B}$ and $8 \mathrm{D})$. 


\section{Other sources of fibre in association with CHD or CVD risk}

Too few studies reported results for fibre fractions or from other sources to permit pooling, but findings from one study suggested a possible protective association for cellulose and lignin intake for fatal CHD risk. However, this association was not evident when non-fatal myocardial infarction events were combined with the fatal CHD cases. ${ }^{22}$ The EPIC Heart study did not report a protective association for "other fibre" (that is, derived from non-cereal, vegetable, or fruit sources) - nor did the Zutphen Elderly study, which examined both long term and recent legume and potato fibre intake. ${ }^{21}$ A US study reported a protective association for legume fibre in women but not men with fatal CVD risk, ${ }^{43}$ although one UK study did not report protective associations for legume sources of fibre and CHD or CVD risk in women. ${ }^{45}$

\section{Study meta-regression}

Web tables 2-7 present results for meta-regression of prespecified moderator variables. But owing to small numbers of included studies, analyses could have a limited capacity to fully explain potential sources of heterogeneity. These pooled estimates should be interpreted carefully where small numbers of studies were combined or where heterogeneity between studies was high $\left(\mathrm{I}^{2}>75 \%\right)$.

Study subgroup analyses for total dietary fibre intake were stable on the whole and remained protectively associated with risk (web table 2). For CHD risk and total fibre intake, no differences were observed between the sexes; US, European, or other study locations; or studies with varying follow-up periods. CVD risk was not significantly associated with total fibre intake in the two studies that had not assessed fibre using the AOAC method and the two studies that had not included adjustment for alcohol in analyses.

Risk estimates were lower and more often significant when studies assessing AOAC fibre were pooled than when those not using AOAC methods were pooled. However, this pattern was not seen for soluble fibre and CHD risk, with a significant association being seen in the two studies that had not used AOAC methods of fibre estimation (web table 4). It is important to note that fewer studies could be pooled for non-AOAC results, and study locations largely determined the fibre estimation method in each cohort.

\section{Discussion}

A significantly lower risk of $9 \%$ was seen for both CVD and CHD with every additional $7 \mathrm{~g} /$ day of total fibre consumed. Findings were aligned with current recommendations to increase fibre intake and showed a large risk reduction with an achievable increase in daily fibre intake. Because CVD is one of the major causes of death in the UK and prevalence rates among the population are estimated to be around $13-16 \%,{ }^{54}$ small reductions in risk could affect many thousands of individuals. An additional $7 \mathrm{~g}$ of fibre (AOAC) can be provided through eating just one portion of whole grains plus a portion of beans or lentils, or through two to four servings of fruit and vegetables. ${ }^{9}$

Lower risk of CVD was also seen with greater intakes of insoluble, cereal, fruit, and vegetable fibre. In addition, reduced risk for CHD was associated with greater intake of insoluble fibre and fibre from cereal or vegetable foods. Despite risk estimates for the different fibre exposures being in the same direction and overlapping, the confidence intervals of pooled estimates for soluble fibre with CHD or CVD risk and for fibre from fruit with CHD risk spanned the line of no effect.

Our findings relate only to fibre from food intake rather than from fibre isolates or extracts, and any public health messages must therefore reflect this. It is not clear from these observations whether fibre consumed as an extract from certain foods is beneficial and whether randomised controlled trials with clinical endpoints or controlled feeding studies with intermediate outcomes can help answer this question.

Meta-regression highlighted possible differences between studies using AOAC methods and those not using AOAC methods to assess fibre intake. However, the small numbers of studies using non-AOAC methods, the notable geographical differences between these studies, and the likely differences between the main sources of fibre in different cohort populations somewhat limits the ability to draw conclusions.

\section{Results in context of other published reviews}

Our findings are consistent with those of previous reviews but improve on aspects of others that were not systematic reviews of literature, ${ }^{4155}{ }^{56}$ did not explore fibre from key dietary sources,${ }^{57}$ or did not quantify the dose-response association but reported risks for highest compared with lowest consumers. ${ }^{58}$

A recent systematic review identified a lower CVD risk of around $20 \%$ for high fibre consumers and separately for high whole grain consumers, compared with the lowest consumers of each ${ }^{58}$ Because fibre and whole grain consumption are likely to correlate highly, it remains a challenge to identify whether fibre intake is a surrogate marker for whole grain intake and the potential beneficial compounds within grains, or whether it is the fibre component of whole grains that confers the protective associations seen with greater intake. A further explanation for the association may be that lower fibre foods tend to be richer in available carbohydrate, which may detrimentally influence insulin and lipid profiles. ${ }^{59}$ Well conducted clinical trials could elucidate the many potential mechanisms through which both wholegrains and fibre from different foods could act on intermediate endpoints or risk factors for CVD.

\section{Limitations}

Limitations of observational cohort studies include the problem of residual confounding, which also extends to meta-analyses of observational studies. Greater intake of dietary fibre is associated with other healthy behaviours such as greater physical activity and lower smoking rates, ${ }^{39}{ }^{40}$ both of which may independently influence CVD risk. We hypothesise that there is a causal link between dietary fibre and CVD risk, although this cannot be proven using observational studies. Evidence from randomised controlled trials can help to determine links between high fibre diets or constituents of dietary fibre and risk factors for CVD_-but owing to the likely long pathogenesis of $\mathrm{CVD}$, trials of adequate duration and adherence are unlikely to be feasible. However, most of the studies identified here did adjust for important confounders such as age, sex, education or class, and smoking status in their analyses, but not all studies adjusted for other potentially important confounders such as physical activity or other dietary factors. Furthermore, other characteristics associated with high fibre intakes could be at play, such as lower body mass index and lower alcohol intake. However, exploration of these factors, through meta-regression, did not reveal that adjustment for such confounders sufficiently explained the strength or direction of associations observed.

Furthermore, Kaushik, Wolk, and Mozaffarian and colleagues point out that although residual confounding may be a limitation 
for prospective cohorts, it is unlikely because different risk observations were seen for cereal, fruit, and vegetable fibre, despite intakes being highly correlated..$^{42}{ }^{40}$ In light of the differing associations observed, they argue that residual confounding is likely not an issue of concern since all the fibre exposures are related to healthier lifestyles. ${ }^{42} 4950$

Another possible limitation is that the majority of dietary data were collected using food frequency questionnaires, which may adequately characterise dietary patterns but could be limited in terms of describing individual nutrient intakes. One study explored risk of CHD with diet assessed using both food frequency questionnaires and seven day food diaries. A protective association was seen for risk of CHD with fibre assessed from food diaries, but risk was attenuated with fibre estimated by food frequency questionnaires. ${ }^{48}$ The authors suggested that food frequency questionnaires may not capture sufficient heterogeneity within a single population but are appropriate in pooled analyses where a wider range of intakes are collated. ${ }^{48}$

Measurement error in dietary assessment is a persistent problem when assessing associations between diet and diseases. The bias can be large and in either direction. In addition, where errors exist in the measurement of confounders, the bias would work in the direction of confounding, which may either exaggerate or dilute the estimated association. ${ }^{60}{ }^{61}$ However, findings from validation studies using biomarkers suggest that measurement error in dietary exposures will often result in attenuated estimates, which might be quite severe. ${ }^{62}$ For this reason, it is wiser not to place emphasis on the exact risk estimate but consider the general direction and relative magnitude of associations.

Studies assessing fibre intakes using different methods (AOAC or not) were combined. Although direct comparisons may not be appropriate between cohort studies that calculate fibre intake using different analytical methods, the direction of effect and - to some extent - the magnitude of the association may be similar and could therefore be informative when summarising data from multiple studies. For example, in the Health Professionals' Follow-up Study, researchers observed similar protective associations between total myocardial infarction (fatal CHD plus myocardial infarction) and total fibre intake assessed using multiple methods. Risk ratios calculated with the Southgate method (risk ratio 0.76 (95\% confidence interval 0.65 to 0.88$)$ per $10 \mathrm{~g} /$ day increase) and Englyst method (0.74 (0.61 to 0.89$)$ ) were not substantially different from that using the AOAC method (0.81 (0.70 to 0.93$))$. $^{44}$

Our search for studies also did not extend beyond those published in English language. However, our understanding is that only a small proportion of available literature in this area is published in languages other than English.

\section{Strengths}

A major strength of this meta-analysis was the inclusion of prospective studies from multiple online database searches, covering published literature from over two decades. The quality of the meta-analyses was strengthened by generating dose-response curves rather than comparisons of high and low fibre consumers. The physiological consequences of a high fibre diet may depend on the type of fibre and the food source. ${ }^{44}$ Therefore, combining studies that have examined dietary sources of fibre was an additional strength.

Despite some heterogeneity, the findings were notably consistent, with all being in the same direction and many individual study results being significant. This is remarkable given the inclusion of studies from different populations with different dietary habits, which were assessed using different tools.

\section{Summary}

Diets high in fibre—-specifically from cereal or vegetable sources and rich in insoluble type fibre-are significantly associated with lower risk of CHD and CVD and reflect recommendations to increase intake. Greater intake of fruit fibre was also associated with lower CVD risk. These data provide evidence relating to whole food consumption and therefore do not support consumption of foods specifically enriched in cereal or vegetable derived fibre. Evidence relating to soluble or insoluble types of fibre was more limited and further investigation in this area would be of use. A limited evidence base also exists from countries outside the US, Europe, Japan, or Australia.

We thank Iris Gordon for search strategy development and James Thomas for his work developing the database into which all articles were extracted.

Contributors: VJB was the project lead for the main systematic review concerning dietary carbohydrates and cardiometabolic health outcomes. VJB, DET, and CLC searched databases. CPG helped develop search strategies. Article screening was undertaken by VJB, DET, CLC, CELE, and CN. Data extraction was carried out by VJB, DET, DCG, CLC, CELE, and CN. Quality of data extraction and checking was carried out by DET, CN, CLC, and CW. Statistical analysis was undertaken by DCG. DET wrote the manuscript. All authors reviewed the manuscript and contributed to manuscript revisions. VJB is the guarantor for this study.

Funding sources: The main systematic review was funded by the Department of Health for England. The update review was conducted primarily by DET, whose PhD studentship is sponsored by Kellogg Marketing and Sales Company (UK). Funding bodies played no part in article selection, analysis, interpretation; or decision to publish. Kellogg Marketing and Sales Company (UK) sponsored the main author studentship. One author is in receipt of an unrelated project grant from Danone. Funders played no part in article selection, analysis, interpretation, or decision to publish.

Competing interests: All authors have completed the ICMJE uniform disclosure form at www.icmje.org/coi_disclosure.pdf and declare: support from the Department of Health for England and support for DET from Kellogg Marketing and Sales Company (UK) for the submitted work; DCG, CELC, CLC, CN, CW, JEC, CPG, and VJB have no financial relationships with any organisations that might have an interest in the submitted work in the previous three years; no other relationships or activities that could appear to have influenced the submitted work.

Ethical approval: Ethical approval was not required for this work.

Data sharing: Details of how to obtain additional data from the study can be obtained from VJB (v.j.burley@leeds.ac.uk).

The lead author affirms that this manuscript is an honest, accurate, and transparent account of the study being reported; that no important aspects of the study have been omitted; and that any discrepancies from the study as planned (and, if relevant, registered) have been explained.

1 Smolina K, Wright FL, Rayner M, Goldacre MJ. Determinants of the decline in mortality from acute myocardial infarction in England between 2002 and 2010: linked national database study. BMJ 2012;344:d8059.

2 Roger VL, Go AS, Lloyd-Jones DM, Benjamin EJ, Berry JD, Boren WB, et al. Heart disease and stroke statistics-2012 update: a report from the American Heart Association. Circulation 2012;125:e2-220.

3 Allender S, Scarborough P, Peto V, Rayner M, Leal J, Luengo-Fernandez R, et al. European cardiovascular disease statistics. 2008. www.bhf.org.uk/publications/viewpublication.aspx?ps=1001443.

4 Unal B, Critchley JA, Capewell S. Explaining the decline in coronary heart disease mortality in England and Wales between 1981 and 2000. Circulation 2004;109:1101-7.

5 Trowell H. Ischemic heart disease and dietary fiber. Am J Clin Nutr 1972;25:926-32. 


\section{What is already known on this topic}

Numerous observational studies have suggested that greater fibre intake is associated with lower risk of cardiovascular disease, but many also report no evidence of any associations

Previous literature reviews have been unsystematic, have only explored total dietary fibre rather than major food sources of fibre, or have not quantified the dose-response association between fibre and risk of cardiovascular disease

\section{What this paper adds}

Our systematic review and meta-analysis suggests that greater intake of total dietary fibre; insoluble type fibre; and fibre from cereal, fruit, or vegetable sources are associated with a lower risk of cardiovascular disease and coronary heart disease in healthy populations These data provide evidence relating to whole food consumption and therefore do not support consumption of foods specifically enriched in cereal or vegetable derived fibre

6 Truswell AS. Cereal grains and coronary heart disease. Eur J Clin Nutr 2002;56:1-14. Van Horn L, McCoin M, Kris-Etherton PM, Burke F, Carson JA, Champagne CM, et al. The evidence for dietary prevention and treatment of cardiovascular disease. J Am Diet Assoc 2008:108:287-331.

8 James SL, Muir JG, Curtis SL, Gibson PR. Dietary fibre: a roughage guide. Intern Med $\rfloor$ 2003;33:291-6.

9 Lunn J, Buttriss JL. Carbohydrates and dietary fibre. Nutr Bull 2007;32:21-64

10 Slavin JL, Martini MC, Jacobs DR Jr, Marquart L. Plausible mechanisms for the protectiveness of whole grains. Am J Clin Nutr 1999;70(3 suppl):459-63S.

11 Slavin J. Whole grains and human health. Nutr Res Rev 2004:17:99-110.

12 COMA. Committee on Medical Aspects of Food Policy, Dietary Reference Values for Food Energy and Nutrients for the United Kingdom. HMSO, 1991.

13 COMA. Committee on Medical Aspects of Food Policy, Nutritional aspects of cardiovascular disease. HMSO, 1994.

14 Stroup DF, Berlin JA, Morton SC, Olkin I, Williamson GD, Rennie D, et al. Meta-analysis of observational studies in epidemiology: a proposal for reporting. Meta-analysis Of Observational Studies in Epidemiology (MOOSE) group. JAMA 2000;283:2008-12.

15 Wells GA, Shea B, O'Connell D, Peterson J, Welch V, Losos M, et al. The Newcastle-Ottawa Scale (NOS) for assessing the quality of nonrandomised studies in meta-analyses. 2013. www.ohri.ca/programs/clinical_epidemiology/oxford.asp.

16 World Cancer Research Fund. Second expert report. Food, nutrition, physical activity and the prevention of cancer: a global perspective. Systematic literature review specification manual. 2007. www.dietandcancerreport.org/cancer_resource_center/downloads/SLR Manual.pdf.

17 Greenland S, Longnecker MP. Methods for trend estimation from summarized dose-response data, with applications to meta-analysis. Am J Epidemiol 1992;135:1301-9.

18 Higgins JP, Thompson SG. Quantifying heterogeneity in a meta-analysis. Stat Med 2002;21:1539-58

19 Bates B, Lennox A, Swan G. National diet and nutrition survey: Headline results from year 1 of the rolling programme. 2008-09. www.food.gov.uk/multimedia/pdfs/publication/ ndnsreport0809.pdf.

20 Larsson SC, Mannisto S, Virtanen MJ, Kontto J, Albanes D, Virtamo J. Dietary fiber and fiber-rich food intake in relation to risk of stroke in male smokers. Eur $\mathrm{J}$ Clin Nutr 2009;63:1016-24

21 Streppel MT, Ocke MC, Boshuizen HC, Kok FJ, Kromhout D. Dietary fiber intake in relation to coronary heart disease and all-cause mortality over $40 \mathrm{y}$ : the Zutphen study. Am J Clin Nutr 2008;88:1119-25

22 Pietinen P, Rimm EB, Korhonen P, Hartman AM, Willett WC, Albanes D, et al. Intake of dietary fiber and risk of coronary heart disease in a cohort of Finnish men. The Alpha-Tocopherol, Beta-Carotene Cancer Prevention Study. Circulation 1996;94:2720-7.

23 Prosky L, Asp NG, Schweizer TF, DeVries JW, Furda I. Determination of insoluble, soluble, and total dietary fiber in foods and food products: interlaboratory study. J Assoc Off Anal Chem 1988;71:1017-23

24 StataCorp. Stata statistical software: release 12. StataCorp, 2011.

25 Egger M, Davey GG, Schneider M, Minder C. Bias in meta-analysis detected by a simple, graphical test. BMJ 1997;315:629-34.

26 Harrell FE Jr, Lee KL, Pollock BG. Regression models in clinical studies: determining relationships between predictors and response. J Natl Cancer Inst 1988;80:1198-202.

27 Orsini N, Greenland S. A procedure to tabulate and plot results after flexible modeling of a quantitative covariate. Stata $J$ 2011;11:1-29.

28 White IR. Multivariate random-effects meta-analysis. Stata J 2009;9:40-56.

29 Drogan D, Hoffmann K, Schulz M, Bergmann MM, Boeing H, Weikert C. A food pattern predicting prospective weight change is associated with risk of fatal but not with nonfatal cardiovascular disease. J Nutr 2007;137:1961-7.

30 Fehily AM, Yarnell JW, Sweetnam PM, Elwood PC. Diet and incident ischaemic heart disease: the Caerphilly study. Br J Nutr 1993;69:303-14

31 Knekt P, Reunanen A, Jarvinen R, Seppanen R, Heliovaara M, Aromaa A. Antioxidant vitamin intake and coronary mortality in a longitudinal population study. Am J Epidemiol 1994;139:1180-9

32 Laaksonen DE, Nyyssonen K, Niskanen L, Rissanen TH, Salonen JT. Prediction of cardiovascular mortality in middle-aged men by dietary and serum linoleic and polyunsaturated fatty acids. Arch Intern Med 2005;165:193-9.

33 Akbaraly TN, Ferrie JE, Berr C, Brunner EJ, Head J, Marmot MG, et al. Alternative healthy eating index and mortality over $18 \mathrm{y}$ of follow-up: results from the Whitehall II cohort. Am J Clin Nutr 2011:94:247-53

34 Appleby PN, Thorogood M, Mann JI, Key TJ. The Oxford Vegetarian Study: an overview. Am J Clin Nutr 1999;70(3 suppl):525-31S.

35 Bazzano LA, He J, Ogden LG, Loria CM, Whelton PK, National Health Nutrition Examination Survey. Dietary fiber intake and reduced risk of coronary heart disease in US men and women: the National Health and Nutrition Examination Survey I Epidemiologic Follow-up Study. Arch Intern Med 2003;163:1897-904.

36 Buyken AE, Flood V, Empson M, Rochtchina E, Barclay AW, Brand-Miller J, et al. Carbohydrate nutrition and inflammatory disease mortality in older adults. Am J Clin Nutr 2010;92:634-43

37 Chuang S-C, Norat T, Murphy N, Olsen A, Tjønneland A, Overvad K, et al. Fiber intake and total and cause-specific mortality in the European Prospective Investigation into Cancer and Nutrition cohort. Am J Clin Nutr 2012;96:164-74.
38 Crowe FL, Key TJ, Appleby PN, Overvad K, Schmidt EB, Egeberg R, et al. Dietary fibre intake and ischaemic heart disease mortality: the European Prospective Investigation into Cancer and Nutrition-Heart study. Eur J Clin Nutr 2012;66:950-6.

39 Eshak ES, Iso H, Date C, Kikuchi S, Watanabe Y, Wada Y, et al. Dietary fiber intake is associated with reduced risk of mortality from cardiovascular disease among Japanese men and women. J Nutr 2010;140:1445-53.

40 Kokubo Y, Iso H, Saito I, Yamagishi K, Ishihara J, Inoue M, et al. Dietary fiber intake and risk of cardiovascular disease in the Japanese population: the Japan Public Health Center-based study cohort. Eur J Clin Nutr 2011;65:1233-41.

41 Liu S, Buring JE, Sesso HD, Rimm EB, Willett WC, Manson JE. A prospective study of dietary fiber intake and risk of cardiovascular disease among women. J Am Coll Cardiol 2002;39:49-56.

42 Mozaffarian D, Kumanyika SK, Lemaitre RN, Olson JL, Burke GL, Siscovick DS. Cereal, fruit, and vegetable fiber intake and the risk of cardiovascular disease in elderly individuals. JAMA 2003:289:1659-66.

43 Park Y, Subar AF, Hollenbeck A, Schatzkin A. Dietary fiber intake and mortality in the NIH-AARP diet and health study. Arch Intern Med 2011;171:1061-8.

44 Rimm EB, Ascherio A, Giovannucci E, Spiegelman D, Stampfer MJ, Willett WC. Vegetable, fruit, and cereal fiber intake and risk of coronary heart disease among men. JAMA 1996;275:447-51.

45 Threapleton DE, Greenwood DC, Burley VJ, Aldwairji M, Cade JE. Dietary fibre and cardiovascular disease mortality in the UK Women's Cohort Study. Eur J Epidemiol 2013:28:335-46.

46 Todd S, Woodward M, Tunstall-Pedoe H, Bolton-Smith C. Dietary antioxidant vitamins and fiber in the etiology of cardiovascular disease and all-causes mortality: results from the Scottish Heart Health Study. Am J Epidemiol 1999;150:1073-80.

47 Wallstrom P, Sonestedt E, Hlebowicz J, Ericson U, Drake I, Persson M, et al. Dietary fiber and saturated fat intake associations with cardiovascular disease differ by sex in the Malmo diet and cancer cohort: a prospective study. PLOS ONE 2012;7:e31637.

48 Ward HA, Keogh R, Lentjes M, Luben RN, Wareham NJ, Khaw KT. Fibre intake in relation to serum total cholesterol levels and $\mathrm{CHD}$ risk: A comparison of dietary assessment methods. Eur J Clin Nutr 2012;66:296-304

49 Wolk A, Manson JE, Stampfer MJ, Colditz GA, Hu FB, Speizer FE, et al. Long-term intake of dietary fiber and decreased risk of coronary heart disease among women. JAMA 1999;281:1998-2004.

50 Kaushik S, Wang JJ, Wong TY, Flood V, Barclay A, Brand-Miller J, et al. Glycemic index, retinal vascular caliber, and stroke mortality. Stroke 2009;40:206-12.

51 Baer HJ, Glynn RJ, Hu FB, Hankinson SE, Willett WC, Colditz GA, et al. Risk factors for mortality in the nurses' health study: a competing risks analysis. Am J Epidemiol 2011;173:319-29.

52 Bernstein AM, Rosner BA, Willett WC. Cereal fiber and coronary heart disease: a comparison of modeling approaches for repeated dietary measurements, intermediate outcomes, and long follow-up. Eur J Epidemiol 2011;26:877-86.

53 Davey GK, Spencer EA, Appleby PN, Allen NE, Knox KH, Key TJ. EPIC-Oxford: lifestyle characteristics and nutrient intakes in a cohort of 33883 meat-eaters and 31546 non meat-eaters in the UK. Public Health Nutr 2003;6:259-69.

54 Townsend N, Wickramasinghe K, Bhatnagar P, Smolina K, Nichols M, Leal J, et al. Coronary heart disease statistics. A conpendium of health statistics. British Heart Foundation health promotion research group. Department of Public Health, University of Oxford, 2012.

55 Hauner $\mathrm{H}$, Bechthold A, Boeing $\mathrm{H}$, Bronstrup A, Buyken A, Leschik-Bonnet $\mathrm{E}$, et al. Evidence-based guideline of the German Nutrition Society: carbohydrate intake and prevention of nutrition-related diseases. Ann Nutr Metab 2012;60(suppl 1):1-58.

56 Pereira MA, O'Reilly E, Augustsson K, Fraser GE, Goldbourt U, Heitmann BL, et al. Dietary fiber and risk of coronary heart disease: a pooled analysis of cohort studies. Arch Intern Med 2004;164:370-6.

57 Mente A, de Koning L, Shannon HS, Anand SS, Mente A, de Koning L, et al. A systematic review of the evidence supporting a causal link between dietary factors and coronary heart disease. Arch Intern Med 2009;169:659-69.

58 Ye EQ, Chacko SA, Chou EL, Kugizaki M, Liu S. Greater whole-grain intake is associated with lower risk of type 2 diabetes, cardiovascular disease, and weight gain. $J$ Nutr 2012;142:1304-13.

59 Liu S, Willett WC, Stampfer MJ, Hu FB, Franz M, Sampson L, et al. A prospective study of dietary glycemic load, carbohydrate intake, and risk of coronary heart disease in US women. Am J Clin Nutr 2000;71:1455-61.

60 Kipnis V, Freedman LS. Impact of exposure measurement error in nutritional epidemiology. $J$ Natl Cancer Inst 2008;100:1658-9.

61 Freedman LS, Schatzkin A, Midthune D, Kipnis V. Dealing with dietary measurement error in nutritional cohort studies. J Natl Cancer Inst 2011;103:1086-92.

62 Kipnis V, Subar AF, Midthune D, Freedman LS, Ballard-Barbash R, Troiano RP, et al. Structure of dietary measurement error: results of the OPEN biomarker study. Am J Epidemiol 2003;158:14-21; discussion 22-6.

Accepted: 11 November 2013

Cite this as: BMJ 2013;347:f6879 
This is an Open Access article distributed in accordance with the Creative Commons Attribution Non Commercial (CC BY-NC 3.0) license, which permits others to distribute, remix, adapt, build upon this work non-commercially, and license their derivative works on different terms, provided the original work is properly cited and the use is non-commercial. See: http://creativecommons.org/licenses/by-nc/3.0/. 


\section{Table}

\section{Table 1 | Characteristics of included cohort studies reporting CVD or CHD risk and fibre intake} Country, recruitment, sex, CHD/CVD endpoints, Dietary assessment (No of
Author and year (cohort baseline age (years), follow-up initial cohort size (No of FFQ items); fibre estimation name) (years)

cases) method

Adjustment for confounding variables

Pietinen $1996^{22}$

(Alpha-Tocopherol

Finland, smokers from

Beta-Carotene Study) randomised controlled trial,

male, 50-69, 6.1

CHD incidence, $n=29133$ Validated FFQ (276) diet over Age, alc, $\beta$-carotene, BMI, blood pressure, (1399) previous year, quality check by nurse; Englyst education, SFA, energy intake, physical activity, smoking, group allocation, vit C, vit E

Rimm $1996^{44}$ (Health US, occupational cohort, male, CHD incidence, $n=51529$ Validated FFQ diet (131) diet Age, alcohol, BMI, SFA, familial MI, smoking, Professionals' Follow-up $40-75,6 \quad(740) \quad$ over previous year; AOAC vit Study)

Appleby $1999^{34}$ (Oxford UK, volunteer cohort (half IDH mortality, $n=11140$ Simple validated FFQ; not $\begin{array}{lll}\text { Vegetarian Study) } & \text { vegetarian), both sexes, } 16-79,(525) & \text { reported, likely to be }\end{array}$ Southgate

Todd $1999^{46}$ (Scottish Scotland, recruited via general CHD incidence, $n=11629$ Validated semi-quantitative
Heart Health Study) practices, both sexes, 40-59, 9 (389) FFQ (60); Englyst and Southgate vit $E$, hypercholesterolaemia, occupation, physical activity, HTN

Wolk $1999^{49}$ (Nurses' Health Study) US, occupational cohort, female, CHD incidence, $n=121$ 30-55, $10 \quad 700(591)$ Validated FFQ (116), diet assessed at least 3 times; AOAC

Age, social class, sex, smoking

Age, serum chol, SBP, carbon monoxide in expired air, El, DM2, BMI, personality, triglycerides, HDLC, fibrinogen, $\mathrm{PA}$, alc

Age, study period, BMI, smoking, menopausal status, aspirin, multivitamin, vit E, PA, HTN, parental early MI, alc, EI, SFA (not fibre source models), $\mathrm{CHO}$. Additional in sources of fibre models: other fibre sources; folate; vit B6, C, and E; $\beta$-carotene; $\mathrm{Mg}$

Liu $2002^{41}$ (Women's US, health professionals from CVD/MI incidence, $n=39$ Validated semi-quantitative Health Study) an RCT, female, mean $54,6 \quad 876(570 / 171)$ FFQ (131); AOAC

Age, treatment group, smoking, PA, alc, HRT, BMI, multivitamins, HTN, history of high chol, DM2, parental MI before age 60 years, folate, fat intake, protein intake, El

Bazzano $2003^{35}$ (NHANES US, sampled to represent $\quad$ CHD incidence, $\mathrm{n}=1440724 \mathrm{~h}$ recall including portion Age, alc, BMI, smoking, edu, eth, DM2, PA,

\begin{tabular}{|c|c|c|c|}
\hline & $25-74,19$ & & to be AOAC \\
\hline $\begin{array}{l}\text { Mozaffarian } 2003^{42} \\
\text { (Cardiovascular Health } \\
\text { Study) }\end{array}$ & $\begin{array}{l}\text { US, random sample from } \\
\text { Medicare register, both sexes, } \\
>65,8.6\end{array}$ & $\begin{array}{l}\text { CHD incidence, } n=5201 \\
(811)\end{array}$ & $\begin{array}{l}\text { Validated FFQ (99) diet over } \\
\text { previous year; AOAC }\end{array}$ \\
\hline $\begin{array}{l}\text { Streppel } 2008^{21} \text { (Zutphen } \\
\text { Elderly Study) }\end{array}$ & $\begin{array}{l}\text { Netherlands, random sample } \\
\text { from industrial town, male, mean } \\
49,13\end{array}$ & $\begin{array}{l}\text { CHD mortality, } n=1373 \\
(348)\end{array}$ & $\begin{array}{l}\text { Diet history, several times, } \\
\text { intake over previous 6-12 } \\
\text { months; AOAC }\end{array}$ \\
\hline $\begin{array}{l}\text { Kaushik } 2009^{50} \text { (Blue } \\
\text { Mountains Eye Study) }\end{array}$ & $\begin{array}{l}\text { Australia, sampled to represent } \\
\text { the region, both sexes, median }\end{array}$ & $\begin{array}{l}\text { CHD mortality, } n=3654 \\
\text { (not reported) }\end{array}$ & Validated FFQ (145); AOAC \\
\hline
\end{tabular}
Mountains Eye Study) the region, both sexes, median (not reported) 65,13

Buyken $2010^{36}$ (Blue Australia, sampled to represent CVD mortality, $n=3654$ Validated FFQ (145); AOAC Mountains Eye Study) the region, both sexes, median (260) 65,13

Validated FFQ (145); AOAC Women: age, El, GI residuals, alc, smoking, DM2; men: age, El, GI residuals, total fat intake, underweight, smoke, use of corticosteroids

Eshak $2010^{39}$ (Japan Collaborative Cohort Study)

Japan, sampled to represent CVD/CHD mortality, general population, both sexes, $n=110792(2080 / 422)$ 40-79, 14.3

Akbaraly $2011^{33}$ (Whitehall UK, occupational cohort, both II) sexes, mean $49,17.7$

CVD mortality, $\mathrm{n}=7319$ (141) similar to $A O A C$

Age, BMI, HTN, DM2, alc, smoking, edu, PA stress, sleep, fish, SFA, n3 fatty acid, sodium intake, folate, vitamins

Age, alc, edu, DM2, PA, sex, smoke; sources of fibre additionally adjusted for other types of fibre

EI, SFA, trans unSFA, cis poly unSFA, alc, wine use, fish intake, prescribed diet, smoking, BMI, SES

Age, sex, SBP, DBP, HTN treatment, BMI, smoking, edu, self rated health, history of $\mathrm{Ml} /$ stroke, DM2

Healthy eating score, sex, age, eth, occ, marital status, smoking, EI, PA, BMI, prevalent CVD, DM2, HTN, dyslipidaemia, metabolic syndrome, inflammatory markers

Baer $2011^{51}$ (Nurses' US, occupational cohort, female, CVD mortality, $n=121$ 30-55, 18 700 (1026)

Validated FFQ (116) Age, BMI at age 18 years, weight change Health Study) administered 3 times; AOAC since age 18 years, height, smoking, $P A$ alc, nut intake, PUFA, GL, chol intake, SBP HTN treatment, DM2, parental early MI, time since menopause

Bernstein $2011^{52}$ (Nurses' US, occupational cohort, female, CHD incidence, $n=72266$ Validated FFQ (116) Age, study period, SFA, MUFA, PUFA, GI, Health Study) 30-55, 22 administered multiple times AOAC 
(continued)

\begin{tabular}{|c|c|c|c|c|}
\hline $\begin{array}{l}\text { Author and year (cohort } \\
\text { name) }\end{array}$ & $\begin{array}{l}\text { Country, recruitment, sex, } \\
\text { baseline age (years), follow-up } \\
\text { (years) }\end{array}$ & $\begin{array}{l}\text { CHD/CVD endpoints, } \\
\text { initial cohort size (No of } \\
\text { cases) }\end{array}$ & $\begin{array}{l}\text { Dietary assessment (No of } \\
\text { FFQ items); fibre estimation } \\
\text { method }\end{array}$ & Adjustment for confounding variables \\
\hline $\begin{array}{l}\text { Kokubo } 2011^{40} \text { (Japan } \\
\text { Public Health Centre } \\
\text { based cohort) }\end{array}$ & $\begin{array}{l}\text { Japan, sampled to represent } \\
\text { population, both sexes, } 40-69 \text {, } \\
10.4\end{array}$ & $\begin{array}{l}\text { CHD mortality, } n=133 \\
323(684)\end{array}$ & $\begin{array}{l}\text { Validated FFQ (138); method } \\
\text { similar to AOAC }\end{array}$ & $\begin{array}{l}\text { Age, sex, smoking, alc, BMI, DM2, HTN/high } \\
\text { chol treatment, PA, fruit, vegetables, fish, } \\
\text { sodium, isoflavone, El, health centre }\end{array}$ \\
\hline $\begin{array}{l}\text { Park } 2011^{43} \text { (NIH-AARP } \\
\text { Diet and Health Study) }\end{array}$ & $\begin{array}{l}\text { US, sampled to represent } \\
\text { general population, both sexes, } \\
50-71,9\end{array}$ & $\begin{array}{l}\text { CVD mortality, } \mathrm{n}=388 \\
122 \text { (7665) }\end{array}$ & $\begin{array}{l}\text { FFQ (124), intake over } \\
\text { previous year AOAC }\end{array}$ & $\begin{array}{l}\text { Age, eth, edu, marital status, health status, } \\
\text { BMI, PA, smoking, alc, red meat, fruit, } \\
\text { vegetables, El (menopausal hormone } \\
\text { therapy use in women) }\end{array}$ \\
\hline Chuang $2012^{37}$ (EPIC) & $\begin{array}{l}\text { Europe, sampled to represent } \\
\text { population, both sexes, mean } \\
50.8,12.7\end{array}$ & $\begin{array}{l}\text { Circulatory disease } \\
\text { mortality, } n=518408 \\
(4604)\end{array}$ & $\begin{array}{l}\text { FFQ, semi-quantitative FFQ, } \\
\text { diet history; AOAC and } \\
\text { standardised values }\end{array}$ & $\begin{array}{l}\text { Age, sex, centre, edu, alc, smoking, BMI, } \\
\text { PA, EI }\end{array}$ \\
\hline $\begin{array}{l}\text { Crowe } 2012^{38} \\
\text { (EPIC-Heart) }\end{array}$ & $\begin{array}{l}\text { Europe, represents general } \\
\text { population, both sexes, mean } \\
53.8,11.5\end{array}$ & $\begin{array}{l}\text { IHD mortality, } \mathrm{n}=519978 \\
(2381)\end{array}$ & $\begin{array}{l}\text { FFQ, semi-quantitative FFQ, } \\
\text { diet history; AOAC and } \\
\text { standardised values }\end{array}$ & $\begin{array}{l}\text { Age, alc, BMI, PA, marital status, edu, occ, } \\
\text { HTN, hyperlipidaemia, angina, DM2, } \\
\text { PUFA:SFA ratio, EI }\end{array}$ \\
\hline $\begin{array}{l}\text { Wallstrom } 2012^{47} \text { (Malmo } \\
\text { Diet and Cancer Cohort) }\end{array}$ & $\begin{array}{l}\text { Sweden, sampled to represent } \\
\text { population, both sexes, } 58,13\end{array}$ & $\begin{array}{l}\text { Ischaemic CVD/CHD } \\
\text { incidence, } \mathrm{n}=28098 \\
\text { (1764) }\end{array}$ & $\begin{array}{l}\text { Interview based diet history } \\
\text { method; non-starch } \\
\text { polysaccharide }\end{array}$ & $\begin{array}{l}\text { Age, diet assessment method version, El, } \\
\text { season, BMI, smoking, edu, alc, SBP, HTN } \\
\text { treatment, antihyperlipidaemic treatment, } \\
\text { leisure PA, level of energy adjusted dietary } \\
\text { fibre }\end{array}$ \\
\hline $\begin{array}{l}\text { Ward 2012 } \\
\text { (EPIC-Norfolk) }\end{array}$ & $\begin{array}{l}\text { UK, sampled to represent } \\
\text { region, both sexes, } 40-79,11\end{array}$ & $\begin{array}{l}\text { CHD incidence, } \mathrm{n}=25639 \\
(2151)\end{array}$ & $\begin{array}{l}\text { FFQ and } 7 \text { day diaries; } \\
\text { Englyst }\end{array}$ & $\begin{array}{l}\text { Age, BMI, PA, smoking, family history MI, } \\
\text { social class, DM2, HTN treatment, lipid } \\
\text { lowering treatment, aspirin, El from total fat, } \\
\text { El from non-fat, alc, SFA, serum chol (total } \\
\text { fibre model only); plasma ascorbic acid level } \\
\text { use in sources of fibre models }\end{array}$ \\
\hline $\begin{array}{l}\text { Threapleton } 2013^{45} \text { (UK } \\
\text { Women's Cohort Study) }\end{array}$ & $\begin{array}{l}\text { UK, volunteer cohort (one third } \\
\text { vegetarian), female, mean } 51.8 \text {, } \\
14.3\end{array}$ & $\begin{array}{l}\text { CVD/CHD mortality, } \mathrm{n}=35 \\
691(258 / 128)\end{array}$ & $\begin{array}{l}\text { Validated FFQ (217); Englyst } \\
\text { and AOAC }\end{array}$ & Age, BMI, SES, smoking, alc, PA, El \\
\hline
\end{tabular}

Alc=alcohol; $\mathrm{BMI}=$ body mass index; $\mathrm{CHO}=$ carbohydrate; chol=cholesterol; $\mathrm{DBP}=$ diastolic blood pressure; $\mathrm{DM} 2=$ diabetes mellitus type 2; edu=education; El=energy intake, EPIC=European Prospective Investigation into Cancer and Nutrition; eth=ethnicity; FFQ=food frequency questionnaire; Gl=glycaemic index; GL Glycaemic Load; HDLC=high density lipoprotein cholesterol; HRT=hormone replacement therapy; HTN=hypertension; IHD=ischaemic heart disease; Mg=magnesium; $\mathrm{Ml}=$ myocardial infarction; MUFA=monounsaturated fatty acid; $\mathrm{NIH-AARP=National} \mathrm{Institutes} \mathrm{of} \mathrm{Health-American} \mathrm{Association} \mathrm{for} \mathrm{Retired} \mathrm{Persons} \mathrm{Diet} \mathrm{and} \mathrm{Health}$ Study; occ=occupation; $\mathrm{PA}=$ physical activity; $\mathrm{PUFA}=$ polyunsaturated fatty acid; $\mathrm{RCT}=$ randomised controlled trial; $\mathrm{SBP}=$ systolic blood pressure; $\mathrm{SES}$ Socioeconomic Status; SFA=saturated fatty acid; vit=vitamin. 


\section{Figures}

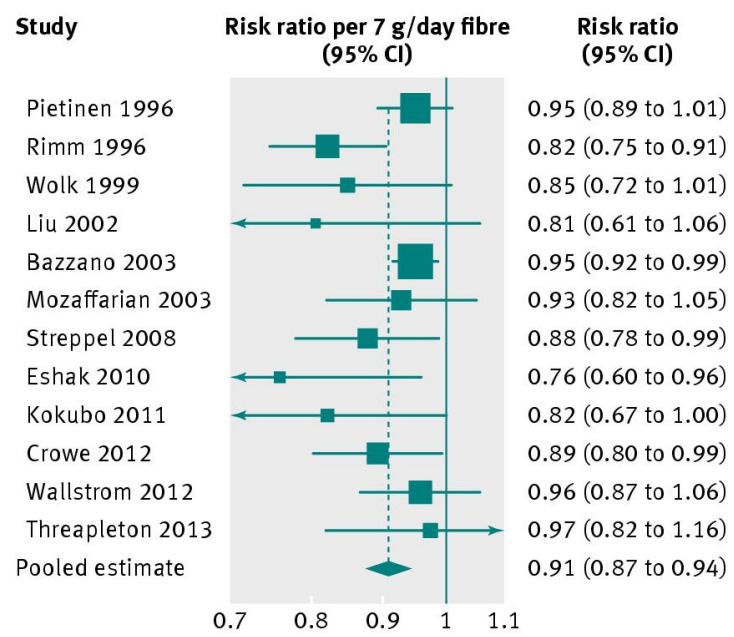

Fig 1 Risk of $\mathrm{CHD}$ associated with each $7 \mathrm{~g} /$ day increase in total fibre intake. RR=risk ratio

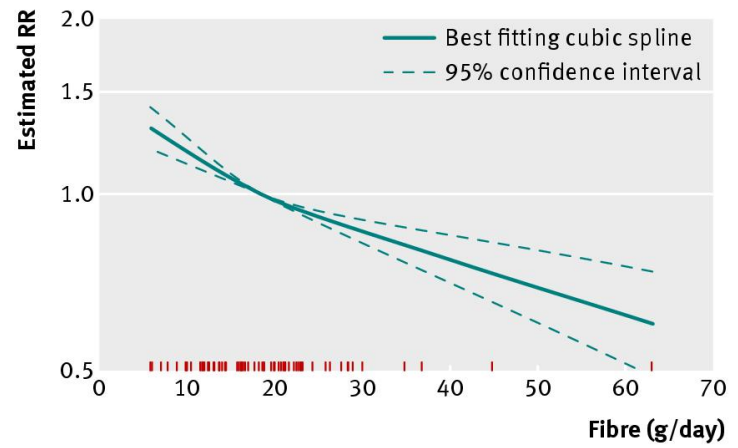

Fig 2 Risk of CHD across increasing levels of total fibre intake. RR=risk ratio

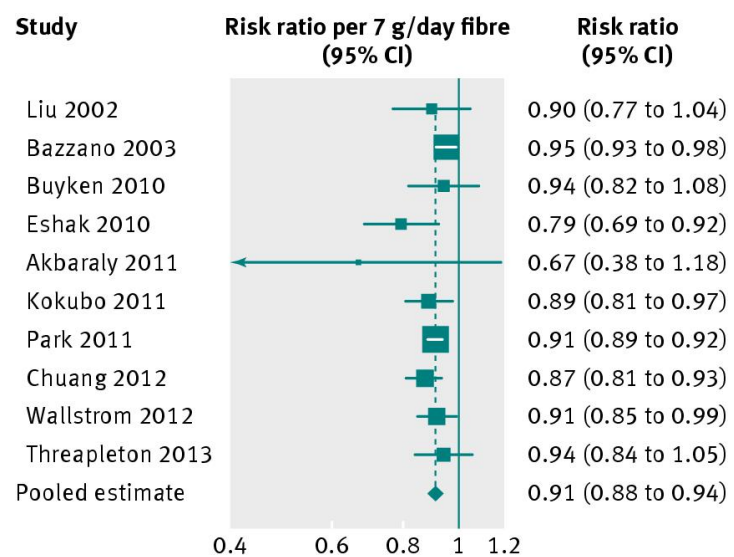

Fig 3 Risk of CVD associated with each $7 \mathrm{~g} /$ day increase in total fibre intake. RR=risk ratio 


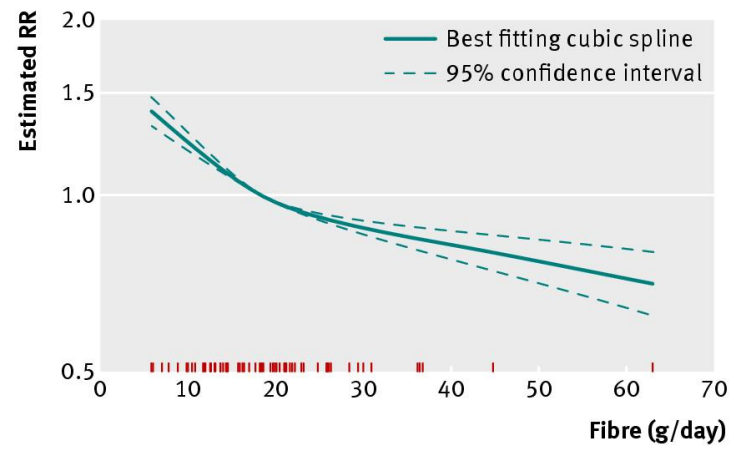

Fig 4 Risk of CVD across increasing levels of total fibre intake. RR=risk ratio

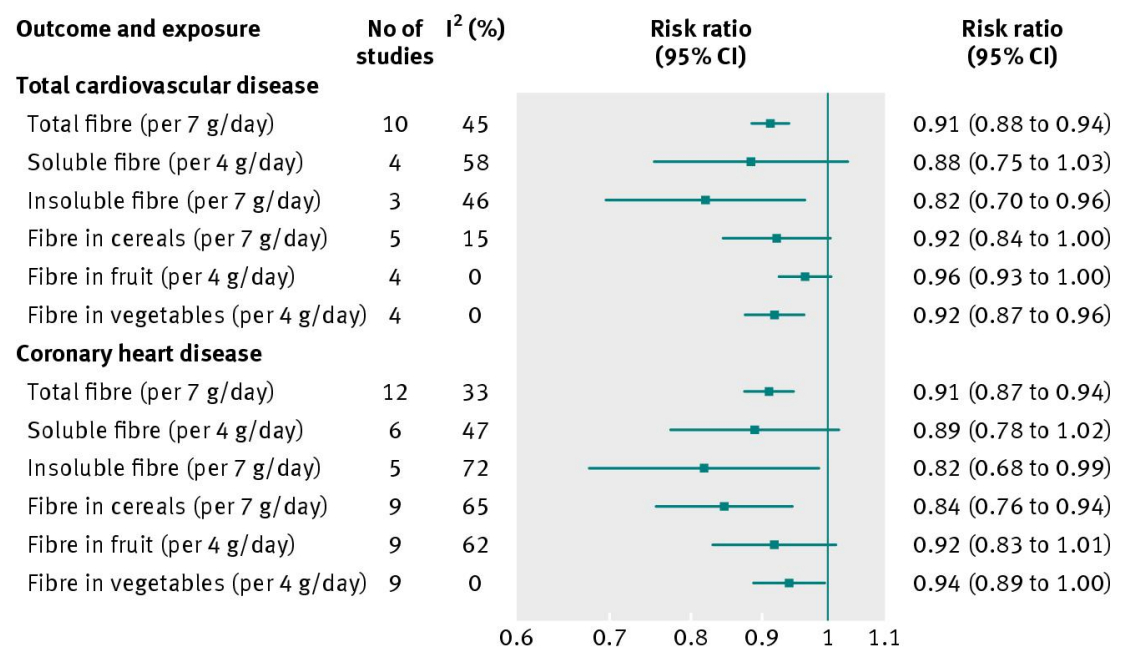

Fig 5 Combined study risk estimates for CHD and CVD associated with greater intake of total fibre, soluble or insoluble fibre and fibre from different food sources. $R R=$ risk ratio 